\title{
Exploring process management: are there any widespread models and definitions?
}

Klara Palmberg

Division of Quality and Environmental Management, Luleå University of Technology, Stockholm, Sweden

\begin{abstract}
Purpose - Process management has been around for a long time, but unlike that of many other management trends, the interest in process management has remained high. The starting point for the study was the idea that the lack of well-established conceptual models and definitions of process management play a role in the challenge and difficulty facing organizations when trying to manage their processes on a strategic level. The purpose of the study was to explore whether there really are some existing widespread and common models and definitions for process management in the literature? The aim of this paper is to describe and explore the findings from the study.

Design/methodology/approach - A structured literature review is used to identify contemporary models and definitions for process management.

Findings - There are several descriptions and definitions of process management presented in the literature, but none that seems to be really widespread and well-established. However, the analysis indicate two different movements: process management for single process improvement; and process management for system management. The results from the literature review are summarized in an aggregated model of existing descriptions of process management. The varying purposes of working with process management demonstrate a diverse need for both movements. Still, the focus of a majority of the identified tools and approaches for process management is to contribute to the more mechanistic movement, the first, of systematically improving single processes.

Originality/value - The paper provides a literature review, the identification of two different movements within process management and presents an aggregated model of existing descriptions of process management. Implications of the findings on process management in organizations are discussed and further research suggested.
\end{abstract}

Keywords Literature, Organizations, Process management, Quality concepts

Paper type Research paper

\section{Introduction}

Process management has been around for a long time, but unlike that of many other management trends, the interest in process management has remained high (Hellström, 2006). There is an ongoing discussion among both practitioners and scholars about how to best manage the value creating flows of activities that run through all organizations.

Numerous process definitions have been proposed through the years, most of them fairly similar. Still, there many disparate views among practitioners regarding the

An earlier version of the article was accepted for and presented at the 11th International QMOD Conference 2008 with the title "In search of well-established models and definitions for process management". 
TQM

21,2

204

concept of processes and process management (Armistead et al., 1999; Belmiro et al., 2000; Isaksson, 2006). Further, when it comes to managing the processes on a system level, process management, the notions and definitions used varies widely (Garvin, 1995; Armistead and Machin, 1997; Pritchard and Armistead, 1999; Ljungberg, 2002; Biazzo and Bernardi, 2003; Hellström and Eriksson, 2007). In addition, the approaches and tools suggested for process management varies both in the literature and in practice and give few clear-cut directions on how to deploy process management (Hellström and Eriksson, 2007).

In parallel, many organizational quality practitioners seem to have grown frustrated about the senior managers' lack of attention on process management. On the other hand, many senior managers still appear to be quite confused regarding why and how to use process management on a strategic, system level (Palmberg, 2005).

The starting point for the study was the idea that the lack of well-established conceptual models and definitions of process management play a role in the challenge and difficulty facing organizations when trying to manage their processes on a strategic level. The purpose of the study was to explore whether there really are some existing widespread and common models and definitions for process management in the literature?

The purpose of this paper is to describe and explore the findings from the study. The findings (descriptions of process management) are structured, analyzed and presented. The results are summarized in an aggregated model, Figure 1, of existing

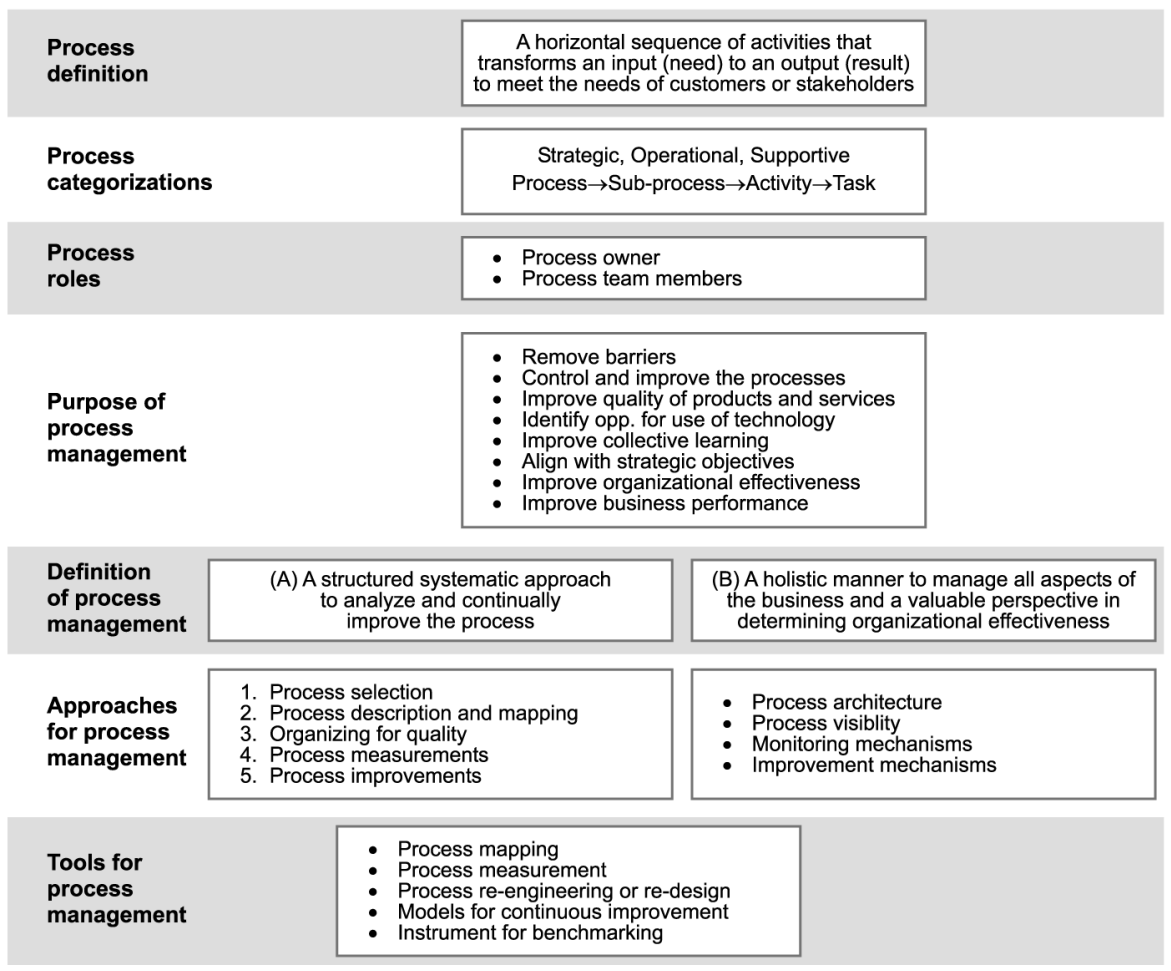

Figure 1.

Model summarizing the result and analysis of the literature review of descriptions of process management
- Process measurement

Process re-engineering or re-design

Instrument for benchmarking 
descriptions of process management. Implications of the findings on process management in organizations are discussed and further research suggested.

\section{Method}

A structured literature review is used to identify contemporary models and definitions for process management. The phrase "process management" is commonly used in several fields of research (Armistead et al., 1999). Searching all fields on any combination of the phrase made 2,747 hits on Emerald, 2099 on EBSCO and 2,276 in Compendex. Based on the number of hits and on convenience Emerald was chosen as the source for the further literature search (see Figure 2).

The search was narrowed down to the exact phrase of process management in keywords or title. This resulted in 223 hits which were sorted on relevance and the work of reading titles and abstracts began. In total, 59 articles were found to be interesting for further review.

A follow-up analysis was performed to examine the content of the articles out of scope. The first 50 articles that were reviewed on title and abstract were examined. The analysis showed that the 27 articles which were found to be out of scope covered: manufacturing and production (13), IT/computer science (4) and in the area of interest for the review, but not in scope for the purpose of the study (10) (see Table I).

The studied articles have been published fairly evenly over the period 1993-2007, see Figure 3. This is in line with Hellström (2006) who concludes that the number of published articles on process management in the management journals has been fairly constant since the 1980s.
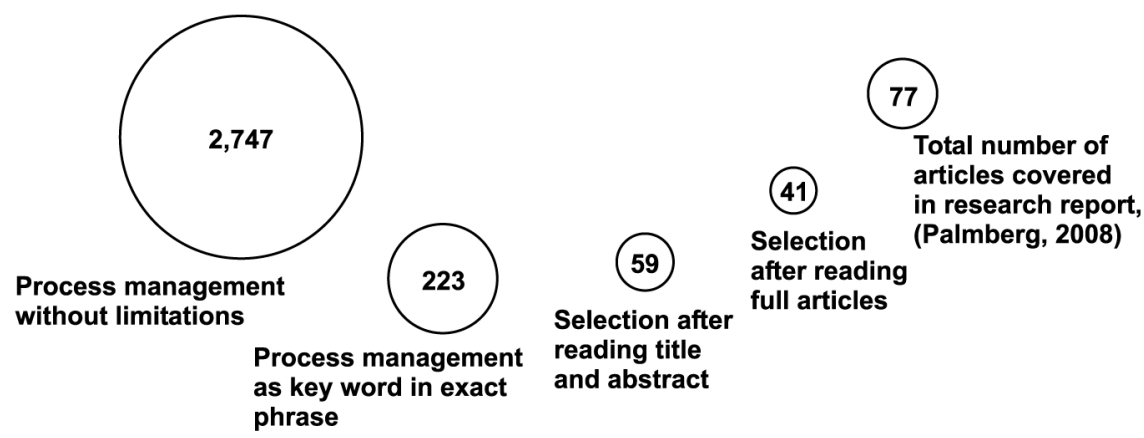

Articles sorted on relevance

Interesting for further review

Out of scope, of which:

Manufacturing and production

IT/computer science

Right field, but out of scope
Article 1 to 50

23
27
13
4
10

Exploring process

management

205
Figure 2.

The number of articles included in the study during different phases
Table I. Number of articles found in Emerald on exact phrase "process management" in title and keyword, sorted on relevance 
TQM

21,2

\section{6}

Figure 3.

Distribution of articles over time in selection after reading title and abstract

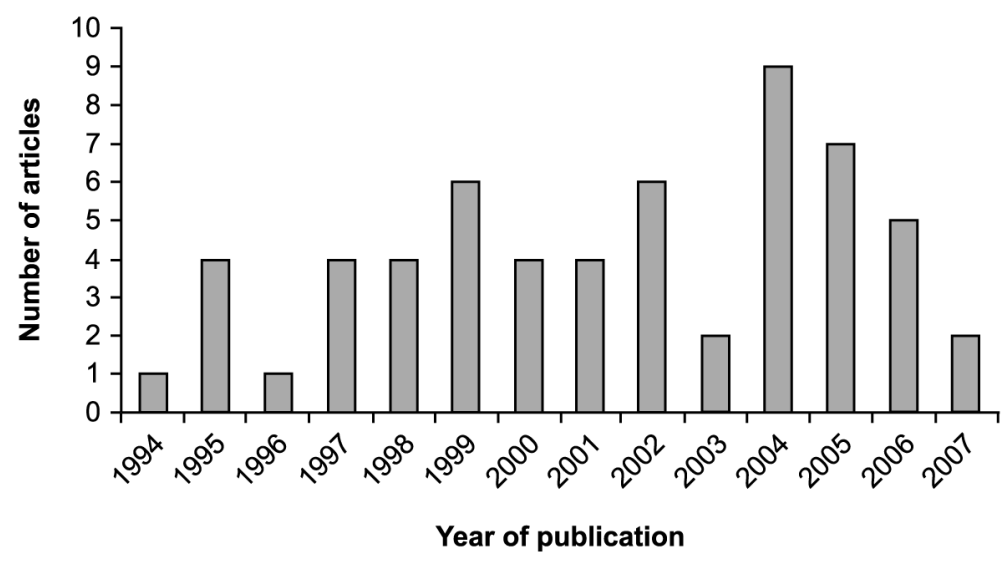

After reading the full articles the selection was narrowed down to 41 items. Additional articles were also identified through references during the reading. In total the review covers 77 full articles, see research report by Palmberg (2008) and Figure 2.

In order to enable a structure for categorization of the found material three areas of interest were selected based on the purpose of the review:

(1) process definitions, categorizations and roles;

(2) definitions of process management; and

(3) approaches and tools for process management.

The text was marked and named with headlines. All quotes were gathered in a research report, using the areas of interest as headlines; see Palmberg (2008).

The analysis has been based on the assembled marks from the articles. When approaching the identified areas of interest a list of second level labels, hypothesis to be analyzed, was iteratively developed, containing questions and areas for analysis such as:

- Area of interest. Process definitions.

- Second level labels. Input and output, Interrelated activities, Cross-functional, Purpose, Repeatability and Use of resources.

In the area of definitions of process management the RADAR[1] logic from the EFQM excellence model (EFQM, 2003) was used as an inspiration to categorize the material:

- Area of interest. Definitions of process management.

- Second level labels. What is process management? What is the purpose, the result (R) to be achieved by using process management? What are the approaches (A) within process management? How process management is deployed (D) - with the use of what tools?

The hypotheses were based on a pre-understanding of both the literature and experience from working with processes management in organizations. 
Results and analysis

The material in the research report was further analyzed and formulated into the following sections.

Process definitions, categorizations and roles

Almost all of the studied authors define "process" in their own words. There seems to be no single definition standing out to be the most broadly spread or most widely used. The differences found between the identified definitions have been reduced to six components that can be seen in a majority of the definitions:

(1) Input and output. Articles that, except the early ones from Davenport and Short (1990) and Harrington (1991), describe the concept of an input that initiates the process and an output which is the result of the process.

(2) Interrelated activities. A majority of the authors describe the components of the process as interrelated activities (Harrington, 1991; Hammer and Champy, 1993; Talwar, 1993; Rentzhog, 1996; Armistead and Machin, 1997; Llewellyn and Armistead, 2000; Ljungberg, 2002; Isaksson, 2006).

(3) Horizontal: intra-functional or cross-functional. Sandhu and Gunasekaran (2004) are the only authors found that define a process as a series of activities that "involves an independent functional unit". A dominating view seems to be that processes are horizontal and cross-functional (see for instance Jacobson, 1995; Armistead and Machin, 1997; Lee and Dale, 1998; Llewellyn and Armistead, 2000).

(4) Purpose or value for customer. Having a process external perspective, including a wider purpose of the process - i.e. to meet the needs of customers, stakeholders or other interested parties. This is mentioned in several articles (such as Davenport and Short, 1990; Harrington, 1991; Hammer and Champy, 1993; Talwar, 1993; Jacobson, 1995; Belmiro et al., 2000; Ljungberg, 2002; Isaksson, 2006).

(5) The use of resources. Mentioned by a few authors (Biazzo and Bernardi, 2003; Isaksson, 2006), who include the use of resources in their definitions.

(6) Repeatability. Mentioned by a few Swedish authors (Rentzhog, 1996; Ljungberg, 2002; Isaksson, 2006).

A gross process definition should, based on the included articles, include all the components above (see Figure 4). A net process definition can be condensed to: A horizontal sequence of activities that transforms an input (need) to an output (result) to meet the needs of customers or stakeholders (see Figure 5).

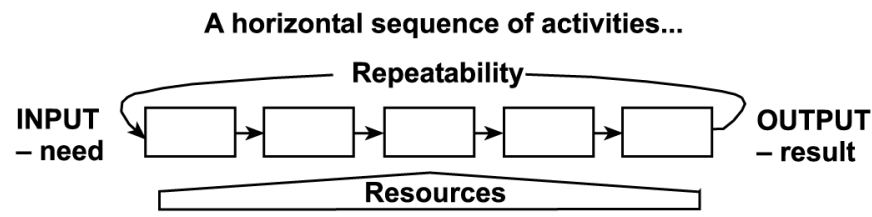

...to meet the needs of customers or stakeholders

Note: The definition includes the components; input and output, interrelated activities, horizontal, purpose, use of resources and repeatability

Figure 4. A gross process definition 
TQM

21,2

208

Figure 5.

A net process definition

Figure 6.

Two ways to categorize processes
In the reviewed articles both categories of processes and hierarchies within processes are described (see Figure 6). The analysis of the reviewed articles has identified three general process categories (see also Davenport, 1993; Jones, 1994; DeToro and McCabe, 1997; Llewellyn and Armistead, 2000; Sandhu and Gunasekaran, 2004; Isaksson, 2006):

(1) Strategic management processes. Covering strategy, planning and control where management oversees and supervises the system (DeToro and McCabe, 1997; Armistead et al., 1999; Chapman, 2001; Sandhu and Gunasekaran, 2004; Isaksson, 2006).

(2) Operational delivery processes. Producing outputs and results for external stakeholders (Jones, 1994; DeToro and McCabe, 1997; Armistead et al., 1999; Isaksson, 2006).

(3) Supportive administrative processes. Required to sustain and support the delivery processes (Jones, 1994; Armistead et al., 1999; Isaksson, 2006).

In a similar way the levels or hierarchy of processes described in the reviewed articles has been summarized into four categories; process, sub-process, activities and tasks (see also Harrington, 1991; Walsh, 1995; DeToro and McCabe, 1997; Lillrank and Liukko, 2004).

Perhaps the most deviant categorization of processes is the "quality broom" described by (Lillrank and Liukko, 2004) which divides processes into standard, routine and non-routine. The level of uncertainty is described to be larger in the non-routine processes and is better managed with a quality culture. While standard

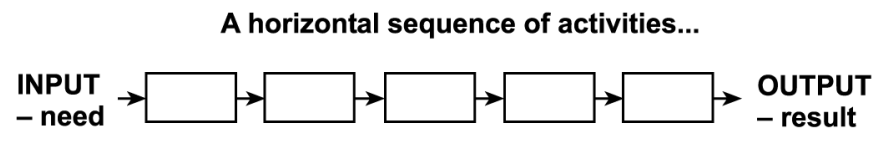

...to meet the needs of customers or stakeholders

Notes: A horizontal sequence of activities that transforms an input (need) to an output (result) to meet the needs of customers or stakeholders. Excluding the components of use of resources and repeatability, only mentioned by a few authors

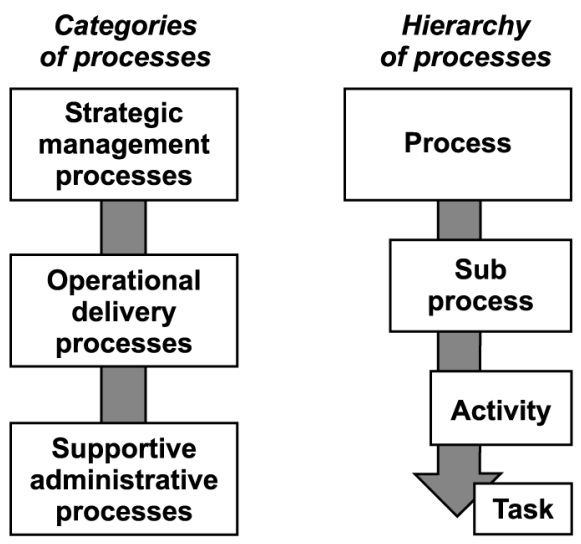


processes with identical repetition and a low level of uncertainty can be managed with quality systems.

There are two process roles described in the reviewed articles. The role of the process owners is described as: accountable for all process improvement results with authority to approve process changes (DeToro and McCabe, 1997), responsible to optimize efficiency and effectiveness, ensuring that external customers' requirements are met (DeToro and McCabe, 1997) and overseeing performance control and continuous improvement (Biazzo and Bernardi, 2003).

The other role described in the literature is the one of the member in cross-functional process teams (DeToro and McCabe, 1997; Lee and Dale, 1998; McAdam and McCormack, 2001). Their role is portrayed by DeToro and McCabe (1997, p. 58) as: "to map and document the process, assess performance, analyze deficiencies, select an improvement strategy, propose design changes, implement fixes, and assess results". The process teams are also described as supporting employee empowerment.

\section{Definitions of process management}

The literature study of definitions of process management gave a large amount of material which was further categorized into a second level of labels.

What is the purpose of process management? As was the case with most of the findings from the literature review there are also differing opinions regarding the purpose of process management:

- to remove barriers between functional groups and bond the organization together (Jones, 1994; Llewellyn and Armistead, 2000);

- to control and improve the processes of the organization (Melan, 1989; Pritchard and Armistead, 1999; Biazzo and Bernardi, 2003; Sandhu and Gunasekaran, 2004);

- to improve the quality of products and services (Melan, 1989; McAdam and McCormack, 2001; Sandhu and Gunasekaran, 2004);

- to identify opportunities for outsourcing and the use of technology to support business (Lindsay et al., 2003; Lock Lee, 2005);

- to improve the quality of collective learning within the organization and between the organization and its environment (Bawden and Zuber-Skerritt, 2002);

- to align the business process with strategic objectives and customer needs (Lee and Dale, 1998); and

- to improve organizational effectiveness and improve business performance (Jones, 1994; Elzinga et al., 1995; Armistead et al., 1999).

There appear to be few major differences in directions or groupings in the reviewed articles regarding the purpose of process management, just a broad variety of arguments for working with it in one way or the other.

What is process management?. Very few of the studied authors thoroughly answer this fundamental question. It appears as though the answer is implicit but widely agreed upon. Still, there seems to be differences in what the authors consider process management to be. The analysis reveals two distinctly different movements; process management for single process improvement and process management for system management (see Figure 7). 
TQM

21,2

210
The first movement, focusing on the management and improvement of single processes, can be summarized into the statement (A): A structured systematic approach to analyze and continually improve the process. This view is shared by (Elzinga et al., 1995; Zairi, 1997; Lee and Dale, 1998; Biazzo and Bernardi, 2003).

A holistic view on process management as a part of managing the whole organization is supported by (Lee and Dale, 1998; McAdam and McCormack, 2001; Bawden and Zuber-Skerritt, 2002). This is described by Pritchard and Armistead (1999, p. 22) as (B): "a more holistic manner to manage all aspects of the business and as a valuable perspective to adopt in determining organizational effectiveness".

Lee and Dale (1998, p. 218) somewhat summarize the two views, (A) and (B) above, as: "Business Process Management is both a set of tools and techniques for improving processes and a method for integrating the whole organization and it needs to be understood by all employees".

\section{Approaches and tools for process management}

Many authors have combined tools and techniques into methodologies and checklists that are of a consulting character, in this paper these are labeled approaches for process management: how to, step by step, work with process management. The analysis of the material shows a divergence in line with the two different movements, $(A)$ and $(B)$, of what process management is (see Figure 7).

The methodology corresponding to the first definition, (A) process management as a structured systematic approach to analyze and continually improve the process, can be summarized as:

(1) Process selection. Based on analysis of the value chain (Pritchard and Armistead, 1999), identifying customers and suppliers (Sinclair and Zairi, 1995), data collection and process targeting (Armistead et al., 1999; Gardner, 2001).

(2) Process description and mapping. Understanding and defining the process (Melan, 1989; Harrington, 1995), key activities (Sinclair and Zairi, 1995) and the process architecture (Pritchard and Armistead, 1999; Armistead et al., 1999).

(3) Organizing for quality. Establishing ownership of the process, defining and appointing process owners (Melan, 1989; Harrington, 1995; Armistead et al., 1999; Pritchard and Armistead, 1999).

(4) Process measurements and quantifications. Identifying performance measurements and targets for controlling the process (Melan, 1989; Jones, 1994; Harrington, 1995; Sinclair and Zairi, 1995; Armistead et al., 1999; Pritchard and Armistead, 1999).

(5) Process improvements. Identifying process improvements, e.g. based on measurements and taking corrective actions (Melan, 1989; Jones, 1994;
Figure 7.

Two different movements in what the authors consider process management to be
(A) Process management for single process improvement

A structured systematic approach to analyze and continually improve the process
(B) Process management for system improvement

A holistic manner to manage
all aspects of the business
and a valuable perspective in
determining organizational
effectiveness


Harrington, 1995; Armistead et al., 1999; Pritchard and Armistead, 1999), including management of the improvement process and methodology (Jones, 1994).

Lock Lee (2005) presents a methodology that is focused on the design and implementation of software products supporting business processes. This is in line with definition (A) of process management, but with a strong focus on the purpose of identifying opportunities for outsourcing and the use of technology to support business suggested by Lock Lee (2005) and Lindsay et al. (2003).

There were hardly any methodologies found that support definition (B) of process management as a more holistic manner to manage all aspects of the business and as a valuable perspective to adopt in determining organizational effectiveness. In Biazzo and Bernardi (2003) a methodology is described by four strategic decision-making areas that form, what the authors call, a process management system:

(1) Process architecture. The constitutive component of a PM system where you describe the processes in the organization in a holistic and systematic manner.

(2) Process visibility. Divided into two dimensions: the relationship between the process architecture and the organizational structure; and the formalization of the functioning of the processes which gives them operating visibility.

(3) Monitoring mechanisms. The design of a performance measurement system that will examine and evaluate process performance. With performance indicators that reflects the strategic objectives of the organization.

(4) Improvement mechanisms. The approaches that determine how plans for change will be selected, launched and managed. They should structurally link improvement activities to the daily work and make organizational change systemic and systematic.

The components presented by Biazzo and Bernardi (2003) bear a resemblance to the methodologies that supports the definition (A) but with an emphasis on holism and the connection between the work with processes and the strategic objectives of the organization.

The tools suggested to be used when working with process management are diverse: process mapping (McKay and Radnor, 1998; McAdam and McCormack, 2001; Biazzo, 2002; Isaksson, 2006), process measurements (Melan, 1992; Lockamy III and McCormack, 2004), process re-engineering or re-design (Lee and Dale, 1998; DeToro and McCabe, 1997; McKay and Radnor, 1998), models for continuous improvement such as the PDSA-cycle (DeToro and McCabe, 1997; Lee and Dale, 1998) and instruments for benchmarking (DeToro and McCabe, 1997; Lee and Dale, 1998).

\section{Conclusion}

The findings from the literature review, descriptions of process management, are structured and summarized in an aggregated model for process management (Figure 1). The model describes a summary of the process definition, categorizations and roles described in the literature included in the review. Further on it describes process management including purposes and definitions of and approaches and tools for process management. 
TQM

21,2

212
The result and analysis of the literature review shows, in line with earlier research, that there seems to be no really common definition of the concept of processes and process management (Armistead et al., 1999; Belmiro et al., 2000; Isaksson, 2006). Still, there are similar components in the process definitions of the included literature. These can be condensed into a net definition, found above in Figures 5 and 7 and at the top of Figure 1.

There are several descriptions of process management presented in the literature, but none that seems to be really widespread and well-established as a definition. This is in line with what previous research has shown (Garvin, 1995; Armistead and Machin, 1997; Pritchard and Armistead, 1999; Ljungberg, 2002; Biazzo and Bernardi, 2003; Hellström and Eriksson, 2007). However, the result and analysis of the definitions of process management in the included literature shows two different movements, (A) process management for single process improvement and (B) process management for system management (see Figures 1 and 7). This is similar to the two models of process management of (Nilsson, 2003) (described in (Hellström, 2006)) described as;

(1) a more mechanistic orientation that is characterized by a focus on structural element; and

(2) an organic orientation that is strongly related to the people in, and the flexibility of, the process.

\section{Discussion}

The varying purposes of working with process management, described in the covered literature, demonstrate a diverse need for both movements, (A) and (B), of process management. Still, the focus of a majority of the identified tools and approaches for process management is to contribute to the more mechanistic movement (A) of systematically improving single processes. It is a technical and instrumental approach that characterizes the definition of and approach for process management in movement (A).

When it comes to the more holistic movement (B), process management as one of several valuable perspectives in the system management of an organization, hardly any tools and approaches have been found in the literature. Even the identified approaches corresponding to movement (B) can be applied in a linear, mechanistic way - contributing successfully to single process improvements but not as effectively to a strategic and holistic management of the whole organization. This is in correspondence to Lindsay et al. (2003).

The approaches and tools for improving single processes (A) might be mostly suitable for use on an operational level, while the tools and approaches in movement (B) is aiming primarily for the strategic level of an organization. The operational level should be very important for the daily work of process management and improvements throughout the organization, at all levels. As a suggestion, the definition and approaches for movement (B) could be further developed into a model for system management.

It can be discussed whether or not the shortage of approaches and tools for process management on a strategic level is contributing to the often seen confusion and discontent among senior managers regarding the perceived lack of clear results from implementing process management. The lack of a widely recognized model for process management might be a contributing factor to the challenges and difficulties that meet 
leaders when trying to manage organizational processes on a strategic, system level. It can be argued that many organizations today aim at applying process management of both (A) and (B), using the existing tools and approaches that mainly are developed for (A), but largely expect holistic results on a strategic level.

A wider discussion regarding the interests of practitioners and researchers within the field of process management can be introduced, questioning today's strong focus on the technical and instrumental parts of process management; the definition of a process, the levels and categorizations of processes, and the techniques for mapping and documenting processes on an activity level. Many organizations devote extensive resources to web-based documentation systems, presenting their processes in several levels (lately I have seen up to eight such levels) from main processes down to individual tasks - without having a discussion of how to structurally link the process management work to the strategic objectives and priorities of the organizations. It is hardly surprising that the work with process management does not deliver a more holistic manner to manage all aspects of the business and as a valuable perspective to adopt in determining organizational effectiveness.

There might be a risk in losing the overall business perspective when focusing heavily on maps, tools and checklists aiming for documentation, finding a process structure and designing the process organization. A lot of energy in quality functions and process development is aimed at building structures with process owners, process teams and a parallel organization to the traditionally functional organization. It might be important to visualize relationships between the process architecture and the organizational structure and to formalize the functioning of the processes. However, the efforts cannot start here without the strategic discussion and making a standpoint on how process management should contribute to the business performance.

There is a strong need for process management practitioners and researcher to develop and formulate approaches and tools that have the potential to contribute to process management not only on a single process level but on a strategic system level in the organization.

\section{Note}

1. Results, Approach, Deployment, Assessment and Review (EFQM, 2003).

\section{References}

Armistead, C. and Machin, S. (1997), "Implications of business process management for operations management", International Journal of Operations \& Production Management, Vol. 17 No. 9, pp. 886-98.

Armistead, C., Pritchard, J.-P. and Machin, S. (1999), "Strategic business process management for organisational effectiveness", Long Range Planning, Vol. 32 No. 1, pp. 96-106.

Bawden, R. and Zuber-Skerritt, O. (2002), "The concept of process management”, The Learning Organization, Vol. 9 No. 3, pp. 132-8.

Belmiro, T., Gardiner, P., Simmons, J. and Rentes, A. (2000), "practitioners really adressing business processes?”, International Journal of Operations \& Production Management, Vol. 20 No. 10, pp. 1183-202.

Biazzo, S. (2002), "Process mapping techniques and organisational analysis: lessons from sociotechnical system theory", Business Process Management Journal, Vol. 8 No. 1, pp. $42-52$. 
TQM

21,2

214

Biazzo, S. and Bernardi, G. (2003), "Process management practises and quality systems standards: risks and opportunities of the ISO 9001 certification", Business Process Management Journal, Vol. 9 No. 2, pp. 149-69.

Chapman, J.A. (2001), “The work of managers in new organisational contexts", The Journal of Management Development, Vol. 20 No. 1, pp. 55-68.

Davenport, T. (1993), Process Innovation, Harvard Business Press, Boston, MA.

Davenport, T. and Short, J. (1990), "The new industrial engineering; information technology and business process redesign", Sloan Management Review, Vol. 31 No. 4, pp. 11-27.

DeToro, I. and McCabe, T. (1997), "How to stay flexible and elude fads", Quality Progress, Vol. 30 No. 3, pp. 55-60.

EFQM (2003), EFQM Excellence Model, European Foundation for Quality Management, Brussels.

Elzinga, D., Horak, T., Chung-Lee, L. and Bruner, C. (1995), "Business process management: survey and methodology", IEEE Transactions on Engineering Management, Vol. 24 No. 2, pp. 119-28.

Gardner, R. (2001), "Resolving the process paradox", Quality Progress, Vol. 34 No. 3, pp. 51-9.

Garvin, D. (1995), "Leveraging processes for strategic advantage", Harvard Business Review, September-October, pp. 77-90.

Hammer, M. and Champy, J. (1993), Reengineering the Corporation: A Manifesto for Business Revolution, HarperCollins Publisher, New York, NY.

Harrington, H. (1991), Business Process Improvement - The Breakthrough Strategy for Total Quality, Productivity, and Competitiveness, McGraw-Hill, New York, NY.

Harrington, H. (1995), Total Improvement Management - The Next Generation in Performance Improvement, McGraw-Hill, New York, NY.

Hellström, A. (2006), "Conceptions of process management - an anlysis of the discourse in the management literature", paper presented at the 9th International QMOD Conference. Liverpool.

Hellström, A. and Eriksson, H. (2007), "Among fumblers, talkers, mappers, and organizers - four applications of process orientation”, in Hellström, A. (Ed.), On the Diffusion and Adoption of Management Ideas: Findings from Six Empirical Studies in the Quality Field, Chalmers University of Technology, Göteborg.

Isaksson, R. (2006), "Total quality management for sustainable development: process based system models”, Business Process Management Journal, Vol. 12 No. 5, pp. 632-45.

Jacobson, I. (1995), The Object Advantage, Addison-Wesley, Upper Saddle River, NJ.

Jones, C. (1994), "Improving your key business processes", The TQM Magazine, Vol. 6 No. 2, pp. 25-9.

Lee, R. and Dale, B. (1998), "Business process management: a review and evaluation”, Business Process Re-engineering and Management Journal, Vol. 4 No. 3, pp. 214-25.

Lillrank, P. and Liukko, M. (2004), "Standard, routine and non-routine processes in health care”, International Journal of Healthcare Quality Assurance, Vol. 17 No. 1, pp. 39-46.

Lindsay, A., Downs, D. and Lunn, K. (2003), "Business processes - attempts to find a definition”, Information and Software Technology, Vol. 45 No. 15, pp. 1015-19.

Ljungberg, A. (2002), "Process measurement", International Journal of Physical Distribution \& Logistics Management, Vol. 32 No. 4, pp. 254-87.

Llewellyn, N. and Armistead, C. (2000), "Business process management: exploring social capital within processes", International Journal of Service Industry Management, Vol. 11 No. 3, pp. 225-43. 
Lock Lee, L. (2005), "Balancing business process with business practice for organizational advantage", Journal of Knowledge Management, Vol. 9 No. 1, pp. 29-41.

Lockamy, A. III and McCormack, K. (2004), "The development of a supply chain management process maturity model using the concepts of business process orientation", Supply Chain Management: An International Journal, Vol. 9 No. 4, pp. 272-8.

McAdam, R. and McCormack, D. (2001), "Integrating business processes for global alignment and supply chain management", Business Process Management, Vol. 7 No. 2, pp. 113-30.

McKay, A. and Radnor, Z. (1998), "A characterization of a business process", International

Exploring process

management

215

Melan, E. (1989), "Process management: a unifying framework for improvement", National Productivity Review, Vol. 8 No. 4, pp. 395-406.

Melan, E. (1992), Process Management. Methods for Improving Products and Service, McGraw-Hill, New York, NY.

Nilsson, G. (2003), Processorientering och styrning: regler, mål eller värderingar? (Process Orientation and Management Control), Handelshögskolan i Stockholm, Stockholm.

Palmberg, K. (2005), Experiences of Process Management, Department of Business Administration and Social Sciences, Division of Quality and Environmental Management, Luleå University of Technology, Luleå.

Palmberg, K. (2008), In Search of Well Established Models for Process Management; Research Report 2008:1, Division of Quality and Environmental Management, Luleå University of Technology, Luleå.

Pritchard, J. and Armistead, C. (1999), "Business process management: lessons from European business”, Business Process Management Journal, Vol. 5 No. 1, pp. 10-32.

Rentzhog, O. (1996), Core Process Management, Department of Mechanical Engineering, Division of Quality and Technology, Linköping University, Linköping.

Sandhu, M. and Gunasekaran, A. (2004), "Business process development in project-based industry”, Business Process Management, Vol. 10 No. 6, pp. 673-90.

Sinclair, D. and Zairi, M. (1995), "Effective process management through performance measurement, Part III: an integrated model of total quality-based performance measurement", Business Process Re-engineering and Management Journal, Vol. 1 No. 3, pp. 50-65.

Talwar, R. (1993), "Business re-engineering - a strategy driven approach", Long Range Planning, Vol. 26 No. 6, pp. 22-40.

Walsh, P. (1995), "Overcoming chronic TQM fatigue”, The TQM Magazine, Vol. 7 No. 5, pp. 58-64.

Zairi, M. (1997), "Business process management: a boundaryless approach to modern competitivness", Business Process Re-engineering and Management Journal, Vol. 3 No. 1, pp. 64-80.

\section{Corresponding author}

Klara Palmberg can be contacted at: klara.palmberg@1tu.se

To purchase reprints of this article please e-mail: reprints@emeraldinsight.com

Or visit our web site for further details: www.emeraldinsight.com/reprints 